\title{
Prevalence of tinnitus in workers exposed to noise and organophosphates
}

\author{
Camila Ribas Delecrode', Thais Domingues de Freitas², Ana Claúdia Figueiredo Frizzo ${ }^{3}$, Ana Claúdia Vieira Cardoso4. \\ 1) Especialist in Audiology by the Federal Council of Speech Therapy. Speech Therapist of the Faculdade de Filosofia e Ciências of the Universidade Estadual Paulista \\ - UNESP-Marília/SP - Brasil. \\ 2) Graduated in Speech Therapy by Faculdade de Filosofia e Ciências of the Universidade Estadual Paulista - UNESP- Marília/SP - Brasil. Speech Therapist. \\ 3) $\mathrm{PhD}$ in Neurology at the Medical School of Ribeirão Preto- USP. Especialist in Audiology by the Federal Council of Speech Therapy. Professor of the Speech Therapy \\ Department of the Faculdade de Filosofia e Ciências of the Universidade Estadual Paulista - UNESP-Marília/SP - Brasil. \\ 4) PhD in Human Communication Disorders of the São Paulo Federal University - UNIFESP. Especialist in Audiology by the Federal Council of Speech Therapy. Professor \\ of the Speech Therapy Department of Faculdade de Filosofia e Ciências of the Universidade Estadual Paulista - UNESP-Marilia/SP - Brasil. \\ Institution: Faculdade de Filosofia e Ciências da Universidade Estadual Paulista - FFC - UNESP. \\ Marília/SP - Brazil. \\ Mailing address: Camila Ribas Delecrode - Avenida Vicente Ferreira, 1278 - Marília / SP - Brazil - Zip code: 17515-901 - E-mail: crdfono@ hotmail.com \\ Article received in October 24, 2011. Article approved in November 20, 2011.
}

\section{SUMMARY}

Introduction: Research on the workplace has emphasized the effects of noise exposure on workers' hearing, but has not considered the effects of agrochemicals.

Aim: To evaluate and correlate the hearing level and tinnitus of workers exposed simultaneously to noise and organophosphates in their workplace and to measure tinnitus distress on their quality of life.

Method: A retrospective clinical study. We evaluated 82 organophosphate sprinklers from the São Paulo State Regional Superintendence who were active in the fight against dengue and who were exposed to noise and organophosphates. We performed pure tone audiometry and applied the translated THI (Tinnitus Handicap Inventory) questionnaire.

Results: Of the sample, $28.05 \%$ reported current tinnitus or had presented tinnitus, and the workers with tinnitus had an increased incidence of abnormal audiometry. The average hearing threshold for the 4-8-kHz frequency range of the workers with current tinnitus was higher than that of the others, and was most affected at the $4-\mathrm{kHz}$ frequency. The THI score ranged 0-84, with an average score of 13.1. Twelve (52.17\%) workers had THI scores consistent with discrete handicap.

Conclusion: There is an increased incidence of abnormal pure tone audiometry in workers with tinnitus, and its impact on the workers' quality of life was discrete. The correlation between average hearing threshold and tinnitus distress was weak. Keywords: occupational health, hearing, tinnitus, questionnaires, noise, insecticides, organophosphates.

\section{INTRODUCTION}

Occupational exposure to agrochemicals in recent decades has increased based on the need for the management of vectors [1] that are difficult to control and that are responsible for the onset of diseases.

Chemical control of such vectors is one of the methods used by government agencies to prevent the spread of epidemics such as dengue, yellow fever, Chagas' disease, and leishmaniasis, among others; agrochemical sprinklers are the professionals responsible for implementing this measure (1).

The configuration of the hearing loss caused by industrial chemicals such as agrochemicals can be very similar to that observed for ototoxic drugs such as aminoglycosides and cisplatin, and that related to noise.
The usual descriptors of these disorders are very similar: sensorineural hearing loss of 3-6 kHz, with lesions mainly on cochlear hair cells, bilateral, symmetrical, and irreversible (2).

In the literature, studies about the effects of agrochemical exposure on hearing are very rare (3). Therefore, further research is necessary to improve understanding of the combined effects of noise and chemicals on hearing. A greater understanding of the effects of combined exposure would allow the development of more effective prevention strategies against hearing loss (4).

There is evidence that chronic exposure to agrochemicals induces peripheral and central auditory damage, and in cases of combined exposure, noise is a factor that interacts with the agrochemicals, increasing its ototoxic effects, especially at the peripheral level (3).

Combined exposure to noise and chemicals produces significantly greater hearing loss than exposure 
to a single agent; a synergistic effect is observed in combined exposure $(5,6,7)$.

A cross-sectional prevalence study conducted with 98 agrochemical sprinklers, who worked in campaigns to prevent dengue, yellow fever, and Chagas disease, aimed to estimate the incidence of hearing loss in this population. There was a $63.8 \%$ prevalence of hearing loss in workers exposed to agrochemicals only and $66.7 \%$ prevalence in those with simultaneous exposure to agrochemicals and noise. It was verified that the level of hearing loss and extent of the frequency range effect were greater in the combined exposure group (8).

A high prevalence of auditory and vestibular complaints were observed in a study performed with 50 rural workers exposed to organophosphates, suggesting that these substances can affect these systems due to their ototoxic and neurotoxic actions. The authors found that $54 \%$ of the workers presented tinnitus (9).

We may emphasize tinnitus among the effects resulting from hearing loss, which apart from causing problems in the workplace, also has a negative impact on workers' quality of life and those around them (10).

Chronic tinnitus (called "ringing") is a very common audiological symptom (affecting 5-15\% of the population) characterized by an auditory perception unrelated with any physical source (11). This first symptom is a warning of excessive exposure to sound stimulation and may indicate increased susceptibility to damage caused by noise, and is a major symptom in preventing noiseinduced hearing loss and one of the main predictive factors of handicap in workers exposed to noise (12). Excessive exposure to noise is a major risk factor for hearing loss and tinnitus, followed by age and gender (13).

Tinnitus (ringing or roaring in the ears) is a highly non-specific symptom affecting a considerable number of the adult population; it is often, but not always, associated with hearing loss of variable degree, and can be frequently considered an expression of cochlear disorder (14).

As there is no objective method for detecting the presence of tinnitus, nor for determining the severity of the symptoms, the use of questionnaires to assess patients with tinnitus is essential (15). These questionnaires, assessing functional effects, are composed of several items that measure the impact of tinnitus on various aspects of daily life (16). According to some authors, their use ensures greater reliability in the evaluation of tinnitus in comparison with other methods (17).
One of these questionnaires is the Tinnitus Handicap Inventory (THI) proposed by Newman et al. (13) and later translated to Portuguese (18). The selection of the THI (19) was due to its confidence, ratified by high internal consistencies $(13,20)$. Its application is easy, fast (approximately 5 minutes), and reproducible (copyright is not reserved) (13).

This study aimed to evaluate and correlate the hearing level and tinnitus of workers exposed simultaneously to noise and organophosphates in their workplace and to measure tinnitus distress on their quality of life.

\section{Method}

This study was developed in the Department of Audiology of the Center of Studies of Education and Health, College of Philosophy and Sciences, UNESP, Marília, and was authorized by the institution's Ethics and Research Committee (protocol number 0179/ 2010). All participants signed a consent form agreeing to participate.

Ten years ago, the center developed a partnership with the Superintendence of Endemic Disease Control (SUCEN), the local authority linked to the São Paulo State Health Secretary, with the purpose of performing annual audiological evaluations in organophosphate sprinklers in this region. As their main task, these workers carry out vector control using chemical products, namely organophosphates (1). To perform their activities to combat endemic vectors, dengue, and yellow fever, they use Malathion $^{\circledR}$, an organophosphate that is known to be toxic to humans and carcinogenic to animals (8). They use a costal motor sprayer 3-4 hours a day, which emits a noise equivalent to $98.5 \mathrm{~dB}$ (A) (1).

The study was conducted with 82 male workers aged 30 and 59 years who had performed this function over a period ranging 1-24 years (mean 15 years).

The data for this study were collected from May to August in 2010. The study was performed with SUCEN workers active in the fight against dengue who were exposed to noise and organophosphates. Exclusion criteria were alterations to otoscopic inspection that prevented procedures from being performed, presence of conductive or mixed hearing loss (21), type B tympanograms (23), and one of the procedures not being performed.

First, we performed an audiological clinical history. The translated THI (18) was applied when workers reported tinnitus. Developed by Newman et al. in 1996 (13), the 
questionnaire comprises 25 questions that can be answered with "yes" ( 4 points), "no" (0 points), or "sometimes" (2 points), with a score ranging 0-100; the higher the score, greater the impact of tinnitus on the respondent's quality of life. The final score classifies the tinnitus handicap as discrete (0-16 points), mild (18-36), moderate (38-56), severe (58-76), and catastrophic (78-100).

Then, we carried out basic audiological evaluation composed of pure tone audiometry and tympanometry. The pure tone audiometry was performed in a soundisolated booth using a GSI-61 audiometer (GrasonStadler) with TDH-50 supra-aural earphones. The clinical pure tone threshold was tested in the frequency range of $0.25-8 \mathrm{kHz}$. When the threshold found was $25 \mathrm{~dB}$ or greater, we performed bone conduction testing in the $0.5-4-\mathrm{kHz}$ frequency range. The examinations were performed at least 14 hours after the hearing rest. The audiograms were classified based on Ordinance 19 of the Ministry of Labor (22). Given the preventive nature of this technical standard, subjects whose audiogram revealed a hearing threshold of $25 \mathrm{~dB}$ (HL) or less at all frequencies evaluated are considered to be within normal limits. Based on the recommendation of this ordinance, average pure tone thresholds at $0.5,1$, and 2 $\mathrm{kHz}$ and averages at 3, 4, and $6 \mathrm{kHz}$ were used for the audiogram analysis (22).

We used a GSI-38 (Grason-Stadler) with a lowfrequency probe tone such as $226 \mathrm{~Hz}$ to perform the tympanometry. After sealing the ear canal, we carried out the tympanometry, a dynamic measurement of the acoustic impedance that verifies the level of mobility of the tympanic-ossicular system. The results were analyzed and classified based on JERGER (23) to fulfill the exclusion criteria.

Statistical analysis was performed to analyze the relation between the variables: the average of the pure tone threshold of the right and left ears and the extent of tinnitus handicap as classified by Newman et al. (13) was determined using Spearman's rank correlation coefficient in STATISTICA version 7.0. The level of significance ( $\mathrm{p}$-value) was 0.05. Correlation is a measure of the relation among 2 or more variables. Correlation coefficients can range from -1 to +1 . A value of -1 represents a perfect negative correlation and +1 represents a perfect positive correlation. The value of 0 represents no correlation.

\section{Results}

To analyze the results, the sample was divided into 2 groups according to the presence or absence of tinnitus.
Group I was composed of 23 (28.05\%) workers with a mean age of 47 years who complained of tinnitus, and group II was composed of 59 (71.95\%) workers with a mean age of 45 years and without tinnitus.

The most frequent tinnitus characteristics (Table 1) in group I were bilateral (43.48\%) and intermittent (65.2\%).

The relation between tinnitus and hearing loss (Table 2) showed that workers with tinnitus had a higher incidence of abnormal pure tone audiometry (60.87\%).

We analyzed the average threshold of pure tone audiometry for group I (Figure 1) and observed that the thresholds in the $4-8-\mathrm{kHz}$ frequency range were higher than that in the others, and were most affected at the 4$\mathrm{kHz}$ frequency.

While investigating the tinnitus handicap in group I, the THI score ranged $0-84$, with an average score of 13.1. Twelve (52.17\%) workers had THI scores consistent with discrete handicap (Figure 2).

Analysis of the relation between the variables right and left earaverage threshold and tinnitus distress measured by the THI were conducted using Spearman's rank correlation coefficient. The right and left ear average threshold and THI score revealed a weak positive correlation, and this tendency was statistically significant (Table 3).

Table I. Group I tinnitus characteristics.

\begin{tabular}{lcc}
\hline Tinnituscharacteristics & $N$ & $\%$ \\
\hline Location & & \\
Rightear & 3 & 13.04 \\
Leftear & 9 & 39.13 \\
Bilateral & 10 & 43.48 \\
Head & 1 & 4.35 \\
\hline Duration & & \\
Persistent & 8 & 34.8 \\
Intermittent & 15 & 65.2 \\
\hline
\end{tabular}

Table 2. Distribution of presence or absence of tinnitus and pure toneaudiometry results.

\begin{tabular}{lcccc}
\hline Audiometry & \multicolumn{2}{c}{ Tinnitus } & \multicolumn{2}{c}{ Absent } \\
& $N$ & $\%$ & Present & $\%$ \\
\hline Normal & 9 & 39.13 & 29 & 50.00 \\
Abnormal & 14 & 60.87 & 29 & 50.00 \\
\hline Total & 23 & 100.00 & 58 & 100.00 \\
\hline
\end{tabular}




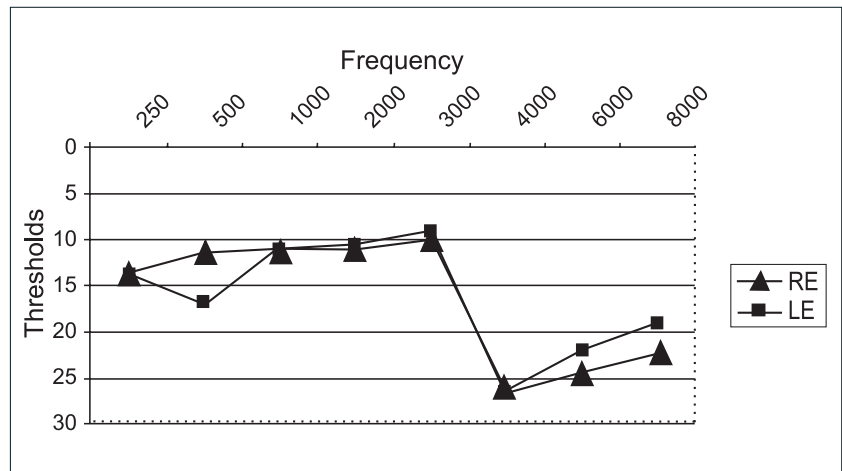

Graphic 1. Average pure tone threshold according to the frequency range for both ears in Group I.

Legend: RE - Right ear, LE - Left ear

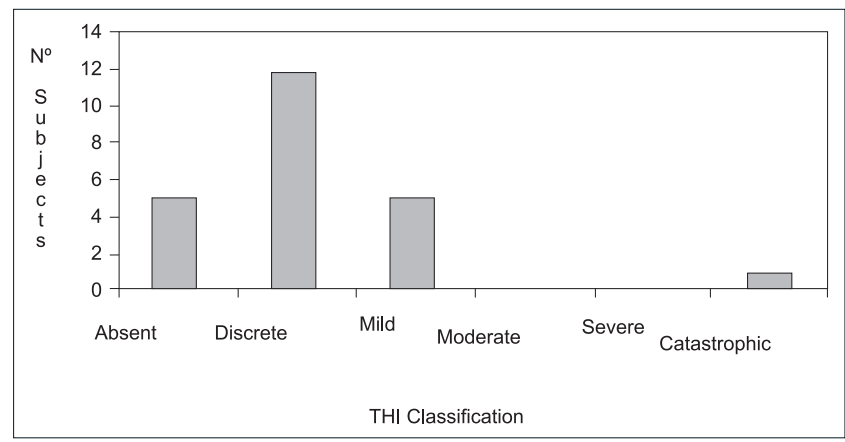

Graphic 2. Distribution of THI results in workers with tinnitus.

Table 3. Correlation between tinnitus distress and right and left ear average threshold

\begin{tabular}{|c|c|c|c|}
\hline CorrelatedVariables & Spearman Coefficient & Sample(N) & $p$ \\
\hline $\begin{array}{l}\mathrm{TH} \times 0.5, \mathrm{I} \text {, and } 2 \mathrm{kHz} \text { Average RE } \\
\mathrm{TH} \times \times 0.5, \mathrm{I} \text {, and } 2 \mathrm{kHz} \text { Average LE } \\
\mathrm{TH} \times 3,4 \text {, and } 6 \mathrm{kHz} \text { Average RE } \\
\mathrm{TH} \times 3,4 \text {, and } 6 \mathrm{kHz} \text { Average LE }\end{array}$ & $\begin{array}{l}0.3597 \\
0.2726 \\
0.2895 \\
0.2937\end{array}$ & $\begin{array}{l}82 \\
82 \\
82 \\
82\end{array}$ & $\begin{array}{l}0.0009 * \\
0.0132 * \\
0.0083 * \\
0.0074 *\end{array}$ \\
\hline
\end{tabular}

Legend: *Level of significance $\mathrm{p}<0.05 / \mathrm{RE}-$ Right ear/LE - Left ear.

\section{DISCUSSION}

Tinnitus is a prevalent problem that remains poorly understood by health professionals. It is a global problem that affects millions of people (24).

In the United States, approximately 50 million adults have tinnitus, and the general prevalence of this symptom in the country is $25.3 \%$. The prevalence of persistent tinnitus is higher among older adults (peak of incidence between 60 and 69 years), non-Hispanic whites, ex-smokers, and hypertensive individuals with hearing loss, exposure to loud sounds, or generalized anxiety disorder (25).

This study showed that $28.05 \%$ of the workers evaluated had tinnitus. This rate is similar to that described by authors who conducted studies with the same population $(6,8,25,26)$, but is below that described in farmers exposed to organophosphates $(9,27)$.

A study verified a significant increase in the probability of individuals with hearing loss at high frequencies $(3,4,6$, and $8 \mathrm{kHz})$ or at low-medium frequencies $(0.5,1$, and $2 \mathrm{kHz})$ having persistent tinnitus when compared to individuals without hearing loss. In individuals with low-medium- or high-frequency hearing loss, noise exposure has been associated with a greater chance of developing persistent tinnitus (25).
A cross-sectional prevalence study, conducted with 98 agrochemical sprinklers who worked in campaigns to prevent dengue, yellow fever, and Chagas disease, aimed to estimate the incidence of hearing loss in this population. There was a $63.8 \%$ prevalence of hearing loss in workers exposed to agrochemicals only and $66.7 \%$ prevalence in those exposed simultaneously to agrochemicals and noise.

A Program of Tinnitus Evaluation and Rehabilitation of a tertiary hospital in Singapore evaluated 327 patients, verifying that the majority (82.6\%) had hearing loss and that it was bilateral in $74 \%$ at frequencies between 3 and $8 \mathrm{kHz}(24)$.

In this study, we observed that the average hearing threshold in workers with hearing loss at the frequencies between 4 and $8 \mathrm{kHz}$ were higher than that in the others, and that the $4-\mathrm{kHz}$ hearing threshold was the most severely affected. A previous study in a similar population reported the presence of hearing loss at frequencies between 3 and $8 \mathrm{kHz}(6,26)$. Another study observed hearing loss in the frequency range between 2 and $8 \mathrm{kHz}$, and hearing loss average values increased from $2-6-\mathrm{kHz}$ frequencies and decreased at $8 \mathrm{kHz}$ when compared to $6 \mathrm{kHz}(8)$.

The audiological findings of hearing loss caused by occupational chemical exposure do not differ from 
noise-induced hearing loss in terms of audiometric configuration. Perhaps this practically identical configuration can justify why this important issue has been neglected for many years. The greatest damage usually occurs at $4 \mathrm{kHz}$, and the higher and lower frequencies are affected more slowly than that within the 3 and $6 \mathrm{kHz}$ range (4).

In a study with workers exposed to several types of agrochemicals, including organophosphates, 2 groups of 42 men were formed (a group composed of agriculture workers with at least 15 years' experience and another composed of workers without agrochemical exposure and without hearing loss history). The results showed that $60 \%$ of the workers exposed to agrochemicals had a lowered hearing threshold, and that 23 of them had bilateral sensorineural hearing loss. The workers with abnormal hearing thresholds exhibited a decrease in the 3-6-kHz frequency range; however, alterations were also observed at frequencies of 1,2 , and $8 \mathrm{kHz}$ (27).

Tinnitus is a highly non-specific symptom affecting a considerable part of the adult population; it is often, but not always, associated with hearing loss of variable degree, and can be frequently considered an expression of cochlear disorder (14).

Tinnitus is followed by outer hair cell damage, which can be very limited, and can occur in individuals with a normal audiometric threshold (11).

Several studies have demonstrated a link between hearing loss and tinnitus. However, there has been no systematic evaluation of the link between perceived tinnitus distress and underlying hearing loss. The underlying hearing loss can be a significant factor in the perception of the distress (29).

Patient distress is a very subjective symptom and frequently depends on external and psychological factors beyond the negative assigned to that of tinnitus (28). The use of an instrument to assess the quality of life of individuals with tinnitus is crucial to choose better treatment and monitoring.

The inclusion of psychometrically robust self-report measures of perceived activity limitation/participation restriction in clinical protocols will continue to prove invaluable in audiological, otologic, and neurotologic clinical practice (30).

This study investigated the tinnitus handicap and the THI score ranged 0-84, with an average score of 13.1 . Twelve (52.17\%) workers had THI scores consistent with discrete handicap. The low handicap found in these workers can be explained by the fact that their tinnitus was intermittent.

A study with similar results reported that the average THI score was 12.3 , and regarding classification, tinnitus in $73.3 \%$ of the individuals was insignificant, while that $20 \%$ was mild, and $6.7 \%$ was moderate. The author justified these findings with the fact that the data were not selected from a specialized medical service, nor had the subjects received any kind of tinnitus treatment. Thus, the author affirmed that the individuals of the study presented low distress caused by tinnitus and demonstrated their ability to change the focus of attention in their daily activities (31).

In a study conducted in a Program of Tinnitus Evaluation and Rehabilitation, researchers applied the THI and found that the score in $33 \%$ of patients was compatible with no handicap, while that in $31 \%$ was mild, 18\% was moderate, and 19\% was severe (24).

Another study using the THI observed that the score for all subjects ranged 0-88 (standard deviation +20.0). The authors reported that both hearing loss and tinnitus were "impairments" resulting from loss or abnormalities of function of the cochlea, vestibulocochlear nerve, or the central auditory pathways. Both these symptoms tended to restrict normal activity (29).

Individuals with tinnitus may suffer several degrees of distress, and this may have a higher or lower impact on the quality of life. Two important factors are related to tinnitus and should be differentiated: the intensity of the tinnitus signal and the severity of the symptom (the distress it causes to the patient's life). The present study agreed with another study that the THI total score can serve as a robust measure of tinnitus distress (32).

The correlation between the right and left ear average threshold and tinnitus distress on quality of life using the THI score revealed a weak positive correlation; there was a tendency for threshold values to increase along with the THI scores, and this tendency was statistically significant.

One study showed that the relationship between the THI score and hearing threshold of the better ear was weak (32).

In the literature, there is no agreement on the link between THI score and hearing threshold. Some studies have demonstrated that there is no correlation between 
tinnitus severity and hearing loss $(24,28)$, but others have confirmed this relationship $(33,34)$.

The correlation between degree of hearing loss and tinnitus distress is related to the way the patient faces his tinnitus, rather than to any physical or anatomical measure (28).

\section{CONCLUSIONS}

This study concluded that there is an increased incidence of abnormal pure tone audiometry in workers with tinnitus who are exposed to noise and organophosphates, the hearing thresholds between 4 and $8 \mathrm{kHz}$ were higher than that for other frequencies, and the $4-\mathrm{kHz}$ frequency was the most affected.

The impact of tinnitus on the workers' quality of life was discrete. The correlation between the average hearing threshold and tinnitus distress was weak, and there was a tendency for threshold values to increase along with THI scores.

\section{REFERENCES}

1. Vilela RAG, Malagoli ME, Morrone LC. Gerenciamento participativo em saúde do trabalhador: uma experiência na atividade de controle de vetores. Saude Soc, 2010; 19(4):969-80

2. Morata TC, Little B. Suggested guidelines for studying the combined effect of occupational exposure to noise and chemicals on hearing. Noise Health, 2002; 4(14):7387.

3. Teixeira CF, da Silva Augusto LG, Morata TC. Occupational exposure to insecticides and their effects on the auditory system. Noise Health, 2002; 4(14):319.

4. Mello AP, Waismann W. Exposição ocupacional ao ruído e químicos industriais e seus efeitos no sistema auditivo: revisão de literatura. Arq. Int. Otorrinolaringol, 2004; 8(3):285-98.

5. Prasher D et al. NoiseChem: An European Commission research project on the effects of exposure to noise and industrial chemicals on hearing and balance. Noise Health, 2002; 4(14):41-8.

6. Guida HL, Morini RG, Cardoso ACV. Avaliaçãoaudiológica em trabalhadores expostos a ruídos e praguicidas. Braz. J. Otorhinolaryngol (impr.), 2010; 76(4):423-27.
7. Fernandes T, Souza MT. Efeitos Auditivos em trabalhadores expostos a ruído e produtos químicos. Rev CEFAC, 2006; 8(2):235-9.

8. Teixeira CF, Augusto LGS, Morata CT. Saúde auditiva de trabalhadores expostos a ruído e inseticidas. Rev Saúde Publica, 2003; 37(4):417-23.

9. Hoshino ACH, Pcheco-Ferreira H, Taguchi CK, Tomita S, Miranda MF. Auto perception of auditory and vestibular healthin workers exposed to organophosphate. Rev. Cefac, 2009; 11(4):681-7.

10. Dias A, Cordeiro R. Interação entre grau de perda auditiva e o incômodo com zumbidos em trabalhadores com história de exposição ao ruído. Rev. Bras. Otorrinolaringol, 2008; 74(6):876-83.

11. Weisz N, Hartmann T, Dohrmann K, Schlee W, Norena A. Highfrequency tinnitus without hearing loss does not mean absence of deafferentation. Hear Res, 2006; 222:108-114.

12. Neuberger M, Korpert K, Raber A, Schwtz F, Bauer P. Hearing loss from industrial noise, head injury and ear disease - a multivariate analysis on audiometric examinations of workers. Audiology, 1992; 31(1):45-57.

13. Newman CW, Jacobson GP, Spitzer JB. Development of the Tinnitus handicap Inventory. Arch Otolaryngol Head Neck Surg, 1996; 122(2):143-8.

14. Borghi C, Modugno GC, Brandolini C, Pirodda A. Is tinnitus useful in early detection of incoming heart decompensation? Med Hypotheses, 2006; 67(3):437-9.

15. Jastreboff, MM, Jastreboff PJ. Questionnaires for Assessment of the Patients and Treatment Outcome. In: Hazell JWP, editor. Proceedings of the Sixth International Seminar. Cambridge (UK): [S.1.]; 1999. p. 487-90.

16. Meikle MB, Stewart BJ, Griest SE, Henry JA. Tinnitus Outcomes Assessment. Trends Amplif, 2008; 12(3):22335.

17. Nunally JC, Bernstein IH. Psychometric theory. $3^{\text {rd }} \mathrm{ed}$. New York: McGraw-Hill; 1994.

18. Ferreira PEA, Cunha F, Onishi ET, Branco-Barreiro FCA, Ganança FF. Tinnitus handicap inventory: adaptação cultural para o Português brasileiro. Pró-Fono, 2005; 17(3):303-10.

19. McCombe A, Baguley D, Coles R, McKenna L, McKinney C, Windle-Taylor P. Guidelines for the grading of tinnitus 
severity: the results of a working group commissioned by the British Association of Otolaryngologists, Head and Neck Surgeons. 1999. Clin Otolaryngol Allied Sci, 2001; 26:38893.

20. Staecker H. Tinnitus evaluation and treatment: assessment of quality of life indicators. Acta Otorhinolaryngol Belg, 2002; 56:355-6.

21. Silman S, Silverman CA. Basic audiologic testing. In: Silman S, Silverman CA. Auditory diagnosis: principles and applications. San Diego: Singular Publishing Group; 1997. p. 44-52.

22. Brasil. Estabelece parâmetros e diretrizes mínimos para a avaliação e acompanhamento da audição de trabalhadores, expostos a níveis de pressão sonora elevados. Portaria no 19 , de 9 de abril de 1998. 1998 abr.

23. Jerger J. Clinical experience with impedance audiometry. Arch Otolaryng, 1970; 92:311.

24. Lim JJBH, Lu PKS, Koh DSQ, Eng SP. Impact of tinnitus as measured by the tinnitus inventory among tinnitus sufferers in Singapure. Med J, 2010; 51(7):551-7.

25. Shargorodsky J, Curhan GC, Farwell WR. Prevalence and characteristics of tinnitus among US adults. Am J Med, 2010; 123(8):711-18.

26. Guida HL, Morini RG, Cardoso ACV. Avaliação audiológica e de emissão otoacústica em indivíduos expostos a ruídos e praguicidas. Arq. Int. Otorrinolaringol, 2009; 13(3):264-69.
27. Manjabosco CW, Morata TC, Marques JM. Perfil Audiométrico de Trabalhadores Agrícolas. Arq. Int. Otorrinolaringol, 2004; 8(4):231-43.

28. Ratnayake S, Jayarajan V, Bartlett J. Could an underlying hearing loss be a significant factor in the handicap caused by tinnitus?. Noise \& Health, 2009; 11(44):156-160.

29. Ferreira LMBM, Ramos Júnior AN, Mendes EP. Caracterização do zumbido em idosos e de possíveis transtornos relacionados. Rev. Bras. Otorrinolaringol, 2009; $75(2): 245-248$.

30. Newman, CW, Sandridge SA; Bolek L† Development and Psychometric Adequacy of the Screening Version of the Tinnitus Handicap Inventory. Otology \& Neurotology, 2008; 29(3):276-81.

31. Acrani IO, Pereira LD. Resolução temporal e atenção seletiva de indivíduos com zumbido. Pró-Fono, 2010; 22(3):233-38.

32. Baguley DM, Andersson G. Factor Analysis of the Tinnitus Handicap Inventory. Am J Audiol, 2003; 12:31-4.

33. Savastano M. Tinnitus with and without hearing loss: are its characteristics different. Eur Arch Otorhinolaryngol, 2008; 265(11):1295-300.

34. Meric C, Gartner M, Collet L, Chéry-Croze S. Psychopathological profile of tinnitus sufferers: evidence concerning the relationship between tinnitus features and impact on life. Audiol Neurootol, 1998; 3(4):240-52. 